\title{
Kepemilikan Kartu Pembayaran Elektronik Tidak Memoderasi Gaya Hidup Hedonis Terhadap Perilaku Impulse Buying
}

\author{
Annisa Dwi Juliastuti, Nur Hasanah, Faizah \\ annisadj13@gmail.com
}

Jurusan Psikologi, Universitas Brawijaya, Malang, Indonesia

\begin{abstract}
Penelitian ini bertujuan untuk mengetahui pengaruh gaya hidup hedonis terhadap perilaku impulse buying dengan kepemilikan kartu pembayaran elektronik sebagai variabel moderasi. Subjek dalam penelitian sebanyak 126 subjek. Teknik pengambilan sampel penelitian ini menggunakan cluster random sampling dan accidental sampling. Hasil analisis data hipotesis pertama menunjukkan nilai $(p)=0.06$, sedangkan hipotesis kedua nilai $(p)=0.000$. Berdasarkan hasil penelitian menunjukkan bahwa kepemilikan kartu pembayaran elektronik tidak memoderasi pengaruh gaya hidup hedonis terhadap perilaku impulse buying, namun sebaliknya gaya hidup hedonis berpengaruh positif terhadap perilaku impulse buying. Semakin tinggi gaya hidup hedonis, maka semakin tinggi pula perilaku impulse buying. Begitu pula sebaliknya, semakin rendah gaya hidup hedonis, maka semakin rendah pula perilaku impulse buying.
\end{abstract}

Kata kunci: gaya hidup hedonis; impulse buying; kepemilikan kartu pembayaran elektronik

\section{Pendahuluan}

Pusat perbelanjaan sebagai tempat segala jenis kebutuhan menjadi tempat yang sering dikunjungi oleh masyarakat. Tingginya minat masyarakat dalam mengunjungi pusat perbelanjaan membuat para pengembang berlomba mendirikan dan mengelola mal, seperti halnya yang terjadi di Surabaya saat ini. Terdapat kurang lebih 26 mal tersebar diseluruh bagian Surabaya sebagai ibu kota Provinsi Jawa Timur (Disperdagin, 2014).

Naentiana dan Setiawan (2014) mengungkapkan bahwa salah satu perilaku pembelian konsumen yang sering terjadi di mal adalah impulse buying. Hal ini juga terjadi di Indonesia. Hal tersebut diketahui berdasarkan hasil survey yang dilakukan oleh Nielsen, dengan sampel responden yang tinggal di Jakarta, Bandung, dan Surabaya, yang menunjukkan bahwa 59 dari 101 responden Jakarta, 68 dari 100 responden Bandung, serta 67 dari 100 responden Surabaya melakukan impulse buying saat berbelanja, di mana mereka terkadang melakukan pembelian produk di luar dari yang yang telah direncanakan (Kharis, 2011).

Impulse buying sendiri adalah pembelian yang tidak rasional dan diasosiasikan dengan pembelian yang cepat dan tidak direncanakan, kemudian diikuti dengan adanya konflik pada pikiran dan dorongan emosional (Verplanken \& Herabadi, 2001). Pembelian tanpa rencana merupakan kegiatan menghabiskan uang yang tidak terkontrol, terutama pada barang-barang yang tidak diperlukan.

Kegiatan belanja saat ini tidak hanya untuk membeli barang yang dibutuhkan atau untuk memenuhi kebutuhan saja, tetapi belanja telah menjadi aktivitas gaya hidup, kesenangan, dan pemenuhan kebutuhan psikologis (Verplanken \& Herabadi, 2001). Hal ini sesuai dengan pernyataan Kotler dan Amstrong (2006) yang menyatakan bahwa terdapat berbagai macam faktor yang mempengaruhi perilaku konsumen termasuk impulse buying, yaitu faktor sosial, faktor personal, faktor psikologi, dan faktor budaya. Di dalam faktor personal sendiri terdapat 
beberapa aspek lain salah satunya adalah gaya hidup.

Gaya hidup menurut Suratno dan Rismiati (2001) adalah pola hidup seseorang dalam dunia kehidupan sehari-hari yang dinyatakan dalam kegiatan, minat dan pendapat yang bersangkutan. Gaya hidup mencerminkan keseluruhan pribadi yang berinteraksi dengan lingkungan. Oleh karena itu, saat ini banyak macam gaya hidup yang berkembang di masyarakat, misalnya gaya hidup hedonis, gaya hidup metropolis, gaya hidup global dan lain sebagainya. Hedonis sendiri adalah pandangan hidup yang menganggap bahwa orang akan menjadi bahagia dengan mencari kebahagiaan sebanyak mungkin dan sedapat mungkin menghindari perasaan-perasaan yang menyakitkan. Hedonis merupakan ajaran atau pandangan bahwa kesenangan atau kenikmatan merupakan tujuan hidup dan tindakan manusia.

Menurut Ma'aruf (Anjani, 2012) kebanyakan konsumen di Indonesia saat ini berorientasi rekreasi yang mementingkan aspek kesenangan, kenikmatan, dan hiburan saat berbelanja. Perilaku pembelian impulsif maupun motivasi yang bersifat emosional memiliki keterkaitan satu sama lain. Pendapat yang sama juga dikemukakan oleh Silvera dkk. (Yistiani, Yasa, \& Suasana, 2012), yang menyatakan bahwa pembelian impulsif adalah kesenangan yang didorong oleh pencapaian tujuan yang bersifat hedonis. Dari penjelasan di atas maka dapat dikatakan bahwa salah satu aspek kehidupan manusia yang diduga dapat mendorong terjadinya kecenderungan dalam impulse buying adalah gaya hidup hedonis.

Brusdal dan Lavik (Bong, 2011) mengungkapkan bahwa seiring meningkatnya kebiasaan masyarakat dalam berbelanja, hal ini didukung pula dengan kemajuan sistem perbankan yang mengeluarkan kartu kredit, kartu debit dan lain-lain, sehingga konsumen berubah menjadi semakin hedonistik dan impulsif.

Santomero dan Seater (1996) mengungkapkan bahwa perkembangan teknologi informasi yang diikuti dengan tingkat persaingan bank yang semakin tinggi mendorong sektor perbankan atau non bank untuk semakin inovatif dalam menyediakan berbagai alternatif jasa pembayaran non tunai berupa system transfer dan alat pembayaran menggunakan kartu elektronik (electronic card payment) atau disingkat (APMK), yang aman, cepat, dan efisien, serta bersifat global.

Menurut Departemen Kebijakan dan Pengawasan (2014), alat pembayaran menggunakan kartu (APMK) adalah seluruh instrumen sistem pembayaran yang pada umumnya berbasis kartu, antara lain kartu Anjungan Tunai Mandiri (ATM), kartu kredit, kartu debet, serta jenis kartu lain yang dapat digunakan sebagai alat pembayaran seperti misalnya kartu smart, $e$-wallet, serta beberapa alat pembayaran lain yang dapat dipersamakan dengan kartu.

Dari fenomena dan paparan di atas, maka peneliti tertarik untuk meneliti lebih mendalam terkait apakah kepemilikan kartu pembayaran elektronik memoderasi pengaruh gaya hidup hedonis terhadap perilaku impulse buying dan apakah gaya hidup hedonis berpengaruh terhadap perilaku impulse buying. Maka dari itu hipotesis yang diajukan dalam penelitian ini adalah kepemilikan kartu pembayaran elektronik memoderasi pengaruh gaya hidup hedonis terhadap perilaku impulse buying dan gaya hidup hedonis mempengaruhi perilaku impulse buying. 


\section{Metode}

\section{Jenis penelitian}

Jenis penelitian yang digunakan pada penelitian ini adalah penelitian dengan pendekatan kuantitatif. Variabel-variabel yang digunakan dalam penelitian ini adalah variabel independen yaitu gaya hidup hedonis, variabel dependen yaitu impulse buying, dan variabel moderasi yaitu kepemilikan kartu pembayaran elektronik. Penelitian ini berfokus untuk mengetahui pengaruh gaya hidup hedonis terhadap perilaku impulse buying dengan kepemilikan kartu pembayaran elektronik sebagai variabel moderasi.

\section{Partisipan penelitian}

Populasi dalam penelitian ini adalah seluruh pengunjung di 26 pusat perbelanjaan di Surabaya. Teknik sampling yang digunakan adalah cluster random sampling untuk menentukkan mal mana yang akan dipakai dalam penyebaran kuesioner dan accidental sampling untuk mengambil subjek di dalam mal. Sampel yang diperoleh sebanyak 126 orang yang diambil di tiga pusat perbelanjaan di Surabaya, yaitu Tunjungan Plaza, Galaxy Mall, dan Royal Plaza.

\section{Data penelitian}

Data penelitian diperoleh dengan menggunakan dua instrumen penelitian, yaitu skala gaya hidup hedonis berdasarkan konsep teori gaya hidup yang dikemukakan oleh William dan Tigert (Engel, Blackwell, \& Miniard, 1993), di mana terdapat tiga aspek dalam gaya hidup hedonis, yaitu interest, activities, dan opini. Instrumen penelitian yang kedua adalah skala perilaku impulse buying berdasarkan elemen-elemen impulse buying yang dikemukakan oleh Verplanken dan Herabadi (2001), di mana terdapat dua elemen penting dalam impulse buying yaitu kognitif dan afektif. Untuk kepemilikan kartu pembayaran elektronik menggunakan model kuesioner tertutup, yaitu pertanyaan terkait kepemilikan kartu pembayaran elektronik dengan opsi jawaban ya atau tidak.

Dari hasil tryout yang dilakukan guna melihat tingkat keabsahan dan keandalan dari aitem-aitem yang ada, untuk skala gaya hidup hedonis didapatkan hasil uji realibilitas Alpha Cronbach sebesar 0.878 dengan jumlah aitem lolos sebanyak 22 aitem. Untuk skala perilaku impulse buying menghasilkan koefisien relibilitas Alpha Cronbach sebesar 0.848 dengan jumlah aitem lolos sebanyak 12 aitem.

\section{Analisis data}

Penelitian ini menggunakan analisis bootstrap moderasi sederhana (Hayes, 2013) dengan resampling sejumlah lima ribu kali dan interval kepercayaan koreksi bias 95\%. Analisis ini dilakukan untuk menguji dua hipotesis, yaitu kepemilikan kartu pembayaran elektronik memoderasi pengaruh gaya hidup hedonis terhadap perilaku impulse buying (H1) dan gaya hidup hedonis mempengaruhi perilaku impulse buying $(\mathrm{H} 2)$.

\section{Hasil}

Hasil menunjukkan bahwa kepemilikan kartu pembayaran elektronik tidak memoderasi pengaruh gaya hidup hedonis terhadap perilaku impulse buying. Hal ini ditunjukkan oleh nilai $\beta$ (koefisien) $=0.004$, $s e=0.002,(p)=0.06$, di mana nilai $(p)>0.05$. Nilai $(p)$ yang dihasilkan tidak signifikan karena $(p)>0.05$.

Tabel 1

Hasil uji hipotesis 1

\begin{tabular}{ccccc}
\hline $\begin{array}{l}\text { Hipo- } \\
\text { tesis }\end{array}$ & $\boldsymbol{\beta}$ & $\boldsymbol{s} \boldsymbol{p}$ & $\boldsymbol{p}$ & Signifikansi \\
\hline H1 & 0.004 & 0.002 & 0.06 & $\begin{array}{c}\text { Tidak } \\
\text { Signifikan }\end{array}$ \\
\hline
\end{tabular}


Tabel 2

Hasil uji hipotesis 2

\begin{tabular}{cccccc}
\hline $\begin{array}{c}\text { Hipo- } \\
\text { tesis }\end{array}$ & $\boldsymbol{\beta}$ & $\boldsymbol{S e}$ & $\boldsymbol{p}$ & $\begin{array}{c}\text { Signi- } \\
\text { fikansi }\end{array}$ & $\begin{array}{c}\boldsymbol{R}- \\
\text { square }\end{array}$ \\
\hline $\mathrm{H} 2$ & 0.428 & 0.045 & 0.000 & $\begin{array}{c}\text { Signi- } \\
\text { fikan }\end{array}$ & $59.26 \%$ \\
\hline
\end{tabular}

Hasil menunjukkan bahwa terdapat pengaruh gaya hidup hedonis terhadap perilaku impulse buying. Hal ini ditunjukkan oleh nilai $\beta$ (koefisien) $=0.428$, se $=0.045$, dan $(p)=0.000$, di mana nilai $(p)<0.05$ maka terdapat pengaruh gaya hidup hedonis yang signifikan terhadap perilaku impulse buying. Nilai $\beta$ (koefisien) yang positif mengindikasikan bahwa pengaruh yang terjadi bernilai positif, hal tersebut menunjukkan bahwa semakin tinggi gaya hidup hedonis, maka semakin tinggi pula perilaku impulse buying. Begitu pula sebaliknya, semakin rendah gaya hidup hedonis, maka semakin rendah pula perilaku impulse buying. Nilai $R$ square yang dihasilkan mencapai angka 0.5926 yang berarti bahwa sumbangan variabel gaya hidup hedonis dalam memprediksi timbulnya perilaku impulse buying pada pengunjung di pusat perbelanjaan Surabaya sebesar $59.26 \%$, sedangkan sisanya $40.74 \%$ (100\%-59.26\%) dipengaruhi oleh faktor lain.

\section{Diskusi}

Hasil pengujian hipotesis pertama menunjukkan bahwa kepemilikan kartu pembayaran elektronik tidak memoderasi pengaruh gaya hidup hedonis terhadap perilaku impulse buying. Hasil ini serupa dengan penelitian yang dilakukan oleh Manek (2014) yang memiliki hasil sama dengan hasil pengujian yang dilakukan oleh peneliti, di mana terbukti bahwa pengaruh credit card yang merupakan salah satu dari bagian kartu pembayaran elektronik terhadap perilaku impulse buying tidak terbukti.

Sama halnya dengan kartu debet/ATM, Lipis, Marrschall, dan Linkers (1992) mengungkapkan bahwa walaupun di satu sisi terdapat manfaat dari kartu ATM/Debet, tetapi di sisi lain terdapat risiko yang perlu disikapi dengan kehati-hatian dari para penggunanya, seperti risiko kartu digunakan oleh pihak lain karena pengguna yang sah kemungkinan melakukan kelalaian dalam penyimpanan kartu dan PIN, lalu berikutnya risiko fraud yang sengaja dilakukan oleh pihak-pihak yang tidak bertanggung jawab dengan mencuri data nasabah pengguna yang tersimpan dalam kartu.

Faktor lain yang juga menyebabkan kartu pembayaran elektronik tidak memoderasi perilaku impulse buying adalah karena dalam penelitian ini responden terbanyak adalah di kisaran usia 18-25 tahun, pendidikan terakhir responden terbanyak adalah lulusan SMA, dan status pendapatan responden terbanyak adalah belum berpendapatan. Hal ini menunjukan bahwa sebagian besar responden berada pada fase perkembangan dewasa awal.

Santrock (2002) mengungkapkan bahwa masa muda (youth) adalah periode dalam membentuk kemandirian ekonomi dan pribadi termasuk pengambilan keputusan. Dari penjelasan tersebut dapat membuktikan bahwa responden yang sebagian besar berada dalam fase perkembangan dewasa awal dan belum berpendapatan atau masih menerima uang bulanan dari orang tua, cenderung untuk lebih berhati-hati dalam mengatur uang bulanan itu sendiri. Orang tua juga turut berperan dalam menentukan cara yang tepat agar anaknya dapat mengatur keuangan secara lebih mandiri, seperti contoh membukakan rekening bank untuk anaknya. Pemberian orang tua yang 
terbatas, menuntut anak untuk bisa mengatur keuangan dengan baik agar kebutuhankebutuhan pokok tidak terbengkalai. Hal ini membuktikan bahwa walaupun memiliki kartu pembayaran elektronik seperti kartu debet/ATM, kartu kredit, dan jenis kartu lain, namun hal tersebut tidak dapat memberikan kontribusi yang kuat dalam memperkuat atau memperlemah pengaruh gaya hidup hedonis terhadap perilaku impulse buying.

Hasil pengujian hipotesis kedua menunjukkan bahwa gaya hidup hedonis berpengaruh positif terhadap perilaku impulse buying. Artinya, semakin tinggi gaya hidup hedonis, maka semakin tinggi pula perilaku impulse buying. Begitu pula sebaliknya, semakin rendah gaya hidup hedonis, maka semakin rendah pula perilaku impulse buying.

Hasil ini didukung oleh Prabowo (Sholihah \& Kuswardani, 2010) yang menjelaskan bahwa faktor-faktor yang mempengaruhi kegiatan belanja termasuk impulse buying adalah gaya hidup. Gaya hidup di sini diartikan sebagai cara seseorang menggunakan waktu yang mengacu pada aktifitas, apa yang dipertimbangkan sebagai hal yang penting di lingkungannya, dan apa yang mereka pikirkan tentang dunia di sekitarnya (Assael, 2001). Gaya hidup yang berkaitan langsung dengan aspek kesenangan dikenal sebagai gaya hidup hedonis dan keinginan konsumen untuk mencari kesenangan hedonisnya dalam berbelanja sering dikaitkan dengan pembelian impulsif (Anjani, 2012).

Hal ini juga sesuai dengan Rook (Park, Eun, \& Judith, 2006) yang mengatakan bahwa perilaku pembelian impulsif sering dipengaruhi oleh beberapa hal, salah satunya adalah pengalaman yang bersifat hedonis. Konsumen yang mendapatkan kesenangan (hedonis) yang relatif tinggi dalam berbelanja, tentu akan meluangkan waktu lebih banyak di toko dan lebih berkeinginan untuk melakukan pembelian daripada yang tidak. Dari penjelasan di atas terlihat bahwa salah satu aspek kehidupan manusia yang diduga dapat mendorong terjadinya kecenderungan dalam impulse buying adalah gaya hidup hedonis, sehingga dapat dikatakan bahwa gaya hidup hedonis berpengaruh positif terhadap perilaku impulse buying.

Keterbatasan dalam penelitian ini yaitu pusat perbelanjaan yang digunakan dalam sampel penelitian kurang mewakili segmentasi pasar perekonomian masyarakat di Surabaya, sehingga dikhawatirkan dapat mempengaruhi hasil dari penelitian. Berikutnya adalah untuk kartu pembayaran elektronik sebagai variabel moderasi kurang spesifik karena dalam penelitian ini mencakup semua kartu pembayaran elektronik seperti kartu debet/ATM dan kartu kredit. Selain itu, banyaknya pengunjung yang menolak untuk mengisi kuesioner cukup menghambat proses pengambilan data, terutama di mal-mal dengan segmentasi perekonomian kelas atas seperti Grand City Mall yang digunakan sebagai tempat pengambilan data untuk tryout dan Galaxy Mall untuk tempat pengambilan data penelitian.

Berdasarkan hasil penelitian dapat ditarik kesimpulan bahwa kepemilikan kartu pembayaran elektronik tidak memoderasi pengaruh gaya hidup hedonis terhadap perilaku impulse buying dan gaya hidup hedonis berpengaruh positif terhadap perilaku impulse buying. Semakin tinggi gaya hidup hedonis, maka semakin tinggi perilaku impulse buying. Begitu pula sebaliknya, semakin rendah gaya hidup hedonis, maka semakin rendah pula perilaku impulse buying. 


\section{Daftar Pustaka}

Anjani, N. L. G. G. (2012). Pengaruh fashion involvement, emosi positif, dan hedonic consumption tendency terhadap pembelian impulsif di department store. Skripsi. Yogyakarta: Universitas Atmajaya Yogyakarta.

Assael, H. (2001). Consumer Behavior $6^{\text {th }}$ Edition. New York: Thomson-Learning.

Bong, S. (2011). Pengaruh in-store stimuli terhadap impulse buying behavior pada konsumen hypermarket di Jakarta. Skripsi. Jakarta: Universitas Multimedia Nusantara.

Departemen Kebijakan dan Pengawasan Sistem Pembayaran. (2014). Data nominal transaksi, volume transaksi, dan jumlah instrumen kartu debet/ATM, kartu kredit, dan e-money. Jakarta: Bank Indonesia.

Engel, J. F., Blackwell, R. D., \& Miniard, D. W. (1993). Perilaku Konsumen Edisi 6 Jilid 1. Terjemahan oleh F.X. Budiyanto. Jakarta: Binarupa Aksara.

Hayes, A. F. (2013). Introduction to Mediation, Moderation, and Conditional Process Modeling. London: The Guilford Press.

Kharis, I. F. (2011). Studi mengenai impulse buying dalam penjualan online. Skripsi. Semarang: Universitas Diponegoro.

Kotler, P. \& Amstrong, G. (2006). Principles of Marketing Tenth Edition. New Jersey: Pearson Prentice Hall.

Lipis, A. H., Marrschall, T. R. \& Linker, J. H. (1992). Perbankan Elektronik (Electronic Banking). Terjemahan oleh A. H. Ali. Jakarta: PT Rineke Cipta.
Manek, N. S. (2014). Pengaruh credit card, window display, discount, dan free product terhadap perilaku impulsive buying di Matahari Departement Store Tunjungan Plaza Surabaya. Jurnal Ilmiah Mahasiswa Universitas Surabaya, 3(2).

Naentiana, P. V. \& Setiawan, P. V. (2014). Peran positive emotion dalam memediasi pengaruh hedonic shopping value terhadap impulse buying. Skripsi. Bali: Universitas Udayana.

Park, E. J., Eun, Y. K., \& Judith, C. F. (2006). A structural model of fashion-oriented impulse buying behavior. Journal of Fashion Marketing and Management, 10(4).

Santomero, A. M. \& Seater, J. J. (1996). Alternative monies and the demand for media of exchange. Journal of Money, Credit, and Banking.

Santrock, J. W. (2002). Life-Span Development: Perkembangan Masa Hidup (Edisi Kelima). Jakarta: Erlangga.

Sholihah, N. A. \& Kuswardani, I. (2010). Hubungan antara gaya hidup hedonis dan konformitas teman sebaya dengan perilaku konsumtif terhadap ponsel pada remaja. Jurnal Universitas Setia Budi.

Suratno, A. \& Rismiati, S. (2001). Pola Hidup pada Lansia. Jakarta: Erlangga.

Verplanken, B. \& Herabadi, A. (2001). Individual differences in impulse buying tendency: feeling and no thinking. European Journal of Personality.

Yistiani, N. Y. M., Yasa, N. Y. K., \& Suasana, I. G. A. (2012). Pengaruh atmosfer gerai dan pelayanan ritel terhadap nilai hedonik dan pembelian impulsif 
pelanggan Matahari Departement Store

Duta Plaza di Denpasar. Jurnal

Manajemen, Strategi Bisnis, dan

Kewiraushaan, 6.

Disperdagin. (2014, 13 April). Diakses pada

16 Februari, 2016, http://disperdagin.

surabaya.go.id/web/index.php/daftar-

pusat-perbelanjaan-di-surabaya. 